\title{
Uso da clorexidina como inibidora de matriz de metaloproteinase na perspectiva do aumento da longevidade de restaurações em resina composta: uma revisão
}

\section{integrativa}

\author{
The use of chlorhexidine as a matrix metalloproteinase inhibitor to increase the longevity of \\ composite resin restorations: an integrative review \\ Uso de la clorhexidina como inhibidor de la metaloproteinasa de la matriz para aumentar la \\ longevidad de las restauraciones de resina compuesta: una revisión integradora
}

Larissa Cristina Pereira Costa

ORCID: https://orcid.org/0000-0002-9609-2549 Centro Universitário de Patos de Minas, Brasil E-mail: larissacosta@unipam.edu.br

Lorene Queiroz Casali Reis

ORCID: https://orcid.org/0000-0001-5551-2255 Centro Universitário de Patos de Minas, Brasil E-mail: lorenepqc@unipam.edu.br

Mariana Vieira Melo

ORCID: https://orcid.org/0000-0003-4458-4485 Centro Universitário de Patos de Minas, Brasil E-mail: marianamelo@unipam.edu.br

Mirelle Estéfane de Oliveira Caixeta ORCID: https://orcid.org/0000-0001-8183-7301 Centro Universitário de Patos de Minas, Brasil E-mail: mireleeoc@unipam.edu.br

Priscila Capelari Orsolin

ORCID: https://orcid.org/0000-0001-7366-7437

Centro Universitário de Patos de Minas, Brasil E-mail: priscilaco@unipam.edu.br

Rodrigo Soares de Andrade

ORCID: https://orcid.org/0000-0001-6114-0929

Centro Universitário de Patos de Minas, Brasil E-mail: rodrigosa@unipam.edu.br

\begin{abstract}
Resumo
Atualmente, um dos grandes desafios para a odontologia adesiva é manter conservada a integridade da camada híbrida em restaurações. É sabido que o fator dificultador está relacionado à ação das matrizes de metaloproteinase (MMP), que degradam os filamentos colágenos desprotegidos. É compreendido que a clorexidina (CHX) se comporta de forma inibitória sobre essa enzima, alterando sua estrutura e quelando os íons metálicos essenciais para sua ativação, o que quebraria essa sequência de degradação. Um dos objetivos deste trabalho foi descrever, com base na literatura, a influência do uso da CHX prévia a aplicação do sistema adesivo perante a conservação da camada hibrida e consequentemente melhora da adesão das resinas compostas. Outro propósito é verificar, entre os sistemas adesivos, se algum elucida melhores resultados após a aplicação da CHX e entender se, em longo prazo, essa inibição se mantém. Essa pesquisa foi realizada na forma de revisão integrativa de literatura, possuindo natureza básica pura. Para tal, foi realizada uma busca pela base de dados "PubMed-NCBI" com os termos de pesquisa: ((clorexidina) and (inibidores de matriz de metaloproteinase)) or (mmp) and (adesivos) considerando publicações dos últimos 10 anos. Perante aos dados coletados fica claro que este ainda é um assunto que demanda maiores e mais longas provas científicas devido a heterogenicidade dos resultados entre autores. Entretanto, nenhum estudo demonstrou que o uso do inibidor seria prejudicial a longevidade da restauração.
\end{abstract}

Palavras-chave: Matriz de metaloproteinase; Clorexidina; Camada híbrida; Adesão; Resina composta.

\begin{abstract}
Currently, one of the greatest challenges for adhesive dentistry is to maintain the integrity of the hybrid layer in restorations. It is known that the complicating factor is related to the action of matrix metalloproteinase (MMP), which degrade unprotected collagen filaments. It is understood that chlorhexidine (CHX) behaves in an inhibitory manner on this enzyme, changing its structure and chelating the metal ions essential for its activation, which would
\end{abstract}


break this degradation sequence. One of the aims of this study was to describe, based on the literature, the influence of the use of CHX prior to the application of the adhesive system on the conservation of the hybrid layer and, consequently, on the improvement of composite resin bonding. Another purpose is to verify, among the adhesive systems, if any elucidates better results after the application of $\mathrm{CHX}$ and to understand if, in the long term, this inhibition is maintained. This research was carried out as an integrative literature review, and is purely basic in nature. To this end, a search was conducted in the "PubMed-NCBI" database with the search terms: ((chlorhexidine) and (matrix metalloproteinase inhibitors)) or ( $\mathrm{mmp}$ ) and (adhesives) considering publications from the last 10 years. Given the data collected it is clear that this is still a subject that requires further and longer scientific evidence due to the heterogeneity of results between authors. However, no study has shown that the use of inhibitors is detrimental to the longevity of the restoration.

Keywords: Metalloproteinase matrix; Chlorhexidine; Hybrid layer; Adhesion; Composite resin.

\section{Resumen}

Actualmente, uno de los mayores retos de la odontología adhesiva es mantener la integridad de la capa híbrida en las restauraciones. Se sabe que el factor de complicación está relacionado con la acción de las metaloproteinasas de la matriz (MMP), que degradan los filamentos de colágeno desprotegidos. Se entiende que la clorhexidina (CHX) se comporta de manera inhibitoria sobre esta enzima, cambiando su estructura y quelando los iones metálicos esenciales para su activación, lo que rompería esta secuencia de degradación. Uno de los objetivos de este trabajo ha sido describir, basándose en la literatura, la influencia del uso de CHX antes de la aplicación del sistema adhesivo para la conservación de la capa híbrida y la consiguiente mejora de la adhesión de las resinas compuestas. Otro propósito es verificar, entre los sistemas adhesivos, si alguno dilucida mejores resultados tras la aplicación de CHX y entender si, a largo plazo, esta inhibición se mantiene. Esta investigación se realizó en forma de revisión bibliográfica integradora, con carácter puramente básico. Para ello, se realizó una búsqueda en la base de datos "PubMed-NCBI" con los siguientes términos de búsqueda: ((clorhexidina) y (inhibidores de la metaloproteinasa de la matriz)) o (mmp) y (adhesivos) considerando las publicaciones de los últimos 10 años. A la vista de los datos recogidos, es evidente que se trata de un tema que requiere más pruebas científicas y más largas debido a la heterogeneidad de los resultados entre los autores. Sin embargo, ningún estudio demostró que el uso del inhibidor fuera perjudicial para la longevidad de la restauración.

Palabras clave: Matriz de metaloproteinasa; Clorhexidina; Capa híbrida; Adhesión; Resina compuesta.

\section{Introdução}

O primeiro avanço da era dos sistemas adesivos foi a realização do ataque ácido em esmalte, idealizado por Buonocore, em 1955. Antes disso, a odontologia se via de frente com uma grande barreira para estabelecer a junção efetiva do material restaurador ao substrato dentário, uma vez que essa união era pela forma mecânica, o que frequentemente tinha um resultado negativo ao longo do tempo (Schmidt, 2019; Tran \& Tran, 2021).

Por apresentar alta composição orgânica e presença de umidade, a dentina ainda apresenta elevadas taxas de insucesso em relação a união do material restaurador. Os tecidos dentários apresentam morfologias bastante distintas, o esmalte, composto basicamente de minerais (96\%) e com estrutura pouco orgânica torna-se fácil à difusão dos adesivos. Por outro lado, a dentina formada por apenas $70 \%$ de minerais, precisa driblar sua umidade natural para proporcionar exposição adequada das fibras colágenas e, consequentemente, embebição efetivamente pelo adesivo (Ten Cate, 1994; Reis \& Loguercio, 2007; Martins et al., 2008).

Mesmo após essa mudança de paradigmas e uma enorme melhora, ainda há uma lacuna no protocolo. O principal fator relacionado a perda da interface dente-resina são as falhas na camada híbrida, formada após a desmineralização da dentina, considerada como fator primordial para que ocorra adequada união (Rajkumar \& Mariswamy, 2021). Por mais que a forma como essas falhas acontecem e como reverte-las ainda não sejam totalmente conhecidos, sabe-se que é imprescindível manter íntegra a matriz de colágeno (Montagner et al., 2014; Medeiros et al., 2019).

Antes dos sistemas adesivos, a adesão era obtida pela criação de macro retenções, o que gerava um desgaste dental ainda maior. Em advento da criação dos mesmos, nasce a Odontologia Adesiva, com intuito de atender a todas as demandas, minimizar a perda dental, melhorar a longevidade das restaurações e gerar uma efetiva aderência. Mas, essa variedade causa uma grande discussão acerca da escolha mais efetiva (Lobo, 2013; Tran \& Tran, 2021). 
Os adesivos autocondicionantes tem o intuito de simplificar a rotina clínica e reduzir a sensibilidade. Esse sistema dispensa o uso do ácido em dentina e consequentemente não é necessário lavar a cavidade, facilitando o controle da umidade da dentina, contudo, possuem mais componentes hidrofílicos (Tran \& Tran, 2021). Já os sistemas adesivos convencionais do tipo condiciona e lava, necessitam da prévia aplicação do ácido, o que torna a manutenção da umidade um dificultador, pelo excesso ou falta de água após a secagem, podendo gerar a hidrólise ou colabação de fibras colágenas dos túbulos dentinários (Martins et al., 2008; Tekçe et al., 2016).

Dessa forma, um desafio para obter uma adesão duradoura é manter estável a camada hibrida (Hashimoto et al., 2010; Tjäderhane et al., 2013), visto que a longo prazo, as fibras colágenas vão se degradando e diminuindo a força de união (Silva et al., 2019; Hamdan-Nassar et al., 2019). Há uma forte hipótese acerca do envolvimento das enzimas de metaloproteinase de matriz (MMP) nessa decomposição. Essa enzima faz parte dos 10\% de proteínas não colágenas presentes na matriz extracelular (MEC) (Mazzoni et al., 2015). As MMP são capazes de degradar quase todos os componentes da MEC (Mazzoni et al., 2015), incluindo o colágeno (Tekçe et al., 2016; Ou et al., 2018).

Por isso, há a constante busca por técnicas que aumentem a qualidade da adesão das restaurações. O digluconato de clorexidina (CHX), como inibidora das MMP, tem mostrado características valiosas na manutenção da camada hibrida. Ela possui amplo espectro e dependendo da sua concentração, se torna bacteriostático ou bactericida (Baehni \& Takeuchi, 2003; Maya et al., 2011; Ou et al., 2018).

Usado inicialmente para controle de biofilme e prevenir gengivite e sendo um antisséptico padrão ouro, a CHX é um eficiente antibacteriano de largo espectro e o mais pesquisado inibidor de MMPs, capaz de inibir pelo menos três delas, a 2, -8, -9 (Baehni \& Takeuchi, 2003; Maya et al., 2011). Mesmo em baixas concentrações, essa substância pode se comportar inibindo as MMPs. A -8 é a que necessita de maior concentração, 0,02\%. Já para a MMP-9, esse número diminui muito e vai para 0,002\%, enquanto a MMP-2, apenas de 0,0001\% (Pashley et al., 2005).

Independente da concentração, deve-se optar pela solução aquosa pura e não pela forma de enxaguantes bucais, que contém conservantes e corantes que podem atrapalhar a adesão (Strobel \& Hellwig, 2015). Outra qualidade da CHX é ter um bom nível de substantividade, que é a sua capacidade de se manter ativa no meio por mais tempo (Liu et al., 2011).

A justificativa para o presente trabalho é o achado rotineiro de restaurações com falha na adesão e, uma das principais causas apontadas, é a ação das MMP que degradam a camada híbrida. Visto isso, muitos estudos têm levantado a hipótese do uso da CHX como inibidor ou retardador dessa enzima, aumentando a estabilidade da camada híbrida, melhorando o prognóstico das restaurações adesivas.

Um dos objetivos deste trabalho foi descrever, com base na literatura, a influência do uso da CHX prévia a aplicação do sistema adesivo perante a conservação da camada hibrida e consequentemente melhora da adesão das resinas compostas. Outro propósito é verificar, entre os sistemas adesivos, se algum elucida melhores resultados após a aplicação da CHX e entender se, em longo prazo, essa inibição se mantém.

\section{Metodologia}

Essa pesquisa foi realizada na forma revisão integrativa de literatura de natureza básica pura, abordada de forma qualitativa e de objetivo descritivo (Estrela, 2018). Para esse fim, foi feita uma criteriosa busca pela base de dados científicos da área da saúde, "PubMed-NCBI". A busca foi realizada por artigos publicados até julho de 2021 e os descritores ((clorexidina) and (inibidores de matriz de metaloproteinase)) or (mmp) and (adesivos) foram selecionados com base na temática da pesquisa, visando resultados relevantes pertinentes à uma revisão integrativa. Esteve limitado a publicações dos últimos 10 anos e que estavam disponíveis os textos completos. Artigos que não empregaram a clorexidina com a finalidade de 
aumentar a adesão em restaurações de resina composta ou as matrizes de metaloproteinases voltadas a odontologia foram excluídos.

\section{Resultados}

Com os descritores citados encontrou-se 2293 estudos. A seleção dos mesmos se deu em três fases, primeiramente a escolha pelo título, 28 artigos, depois pelo seu resumo, 13 artigos, com critério de exclusão não empregar a clorexidina visando o aumento na adesão de restaurações em resina composta. E por último, pelo seu texto completo, 9 artigos priorizados pela relevância, dentre eles, 3 artigos de revisão sistemática, como demonstrado na Figura 1.

Figura 1- Fluxograma do processo de seleção dos estudos.

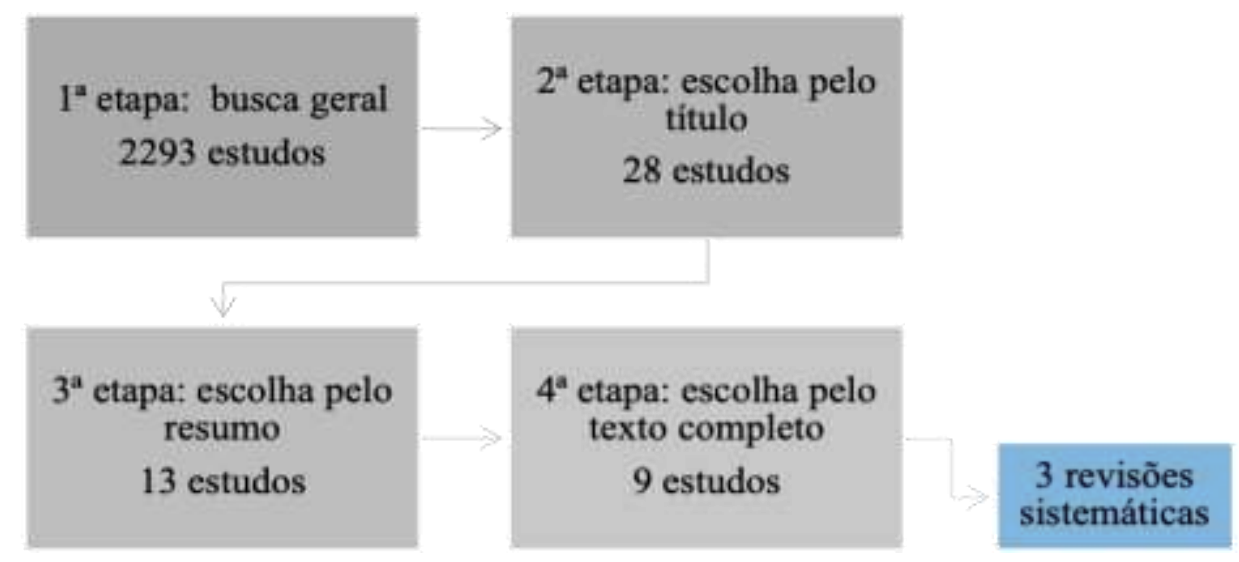

Fonte: Autores.

Com base nos estudos selecionados foi elaborado o Quadro 1, contendo informações sobre ano de publicação, objetivo e resultados ou conclusão, visando gerar maior síntese.

Quadro 1: Estudos selecionados com base na metodologia.

\begin{tabular}{|c|c|c|c|c|}
\hline AUTOR & ANO & $\begin{array}{l}\text { PERIÓDICO DE } \\
\text { PUBLICAÇÃOO }\end{array}$ & OBJETIVO & RESULTADOS/ CONCLUSÃO \\
\hline $\begin{array}{l}\text { Montagner et } \\
\text { al. }\end{array}$ & 2014 & $\begin{array}{l}\text { Journal of Dental } \\
\text { Research }\end{array}$ & $\begin{array}{l}\text { Revisar estudos in } \\
\text { vitro e in vivo que } \\
\text { avaliaram o efeito dos } \\
\text { inibidores de MMP } \\
\text { durante o procedimento } \\
\text { adesivo na resistência de } \\
\text { união imediata e de longo } \\
\text { prazo. }\end{array}$ & $\begin{array}{l}\text { De } 1.336 \text { estudos potencialmente elegíveis, } 48 \text { foram } \\
\text { selecionados para análise de texto completo e } 30 \text { foram } \\
\text { incluídos. Os resultados imediatos da força de união não } \\
\text { mostraram diferença entre } 2 \% \mathrm{CHX} \text { e controle. Contudo, uma } \\
\text { diferença imediata foi encontrada entre } 0,2 \% \text { de CHX e o } \\
\text { controle. Após o envelhecimento, CHX apresentou resistência de } \\
\text { união mais elevada que o grupo controle }(p<0,05) \text {, mas isso não } \\
\text { foi observado por períodos mais longos. Adesivos } \\
\text { autocondicionantes e condicionantes são beneficiados pela } \\
\text { CHX. }\end{array}$ \\
\hline Li et al. & 2015 & $\begin{array}{l}\text { International } \\
\text { Journal of Clinical } \\
\text { and } \\
\text { Experimental } \\
\text { Medicine }\end{array}$ & $\begin{array}{l}\text { Investigar a dentina pré- } \\
\text { tratada com CHX } 2 \% \text { e } \\
\text { minociclina (MI) } 2 \% \text { no } \\
\text { sistemaradesivo } \\
\text { condiciona e lava com } \\
\text { microscopia eletrônica de } \\
\text { varredura para observar a } \\
\text { rede de colágeno e } \\
\text { camada híbrida (DHL). }\end{array}$ & $\begin{array}{l}\text { Quarenta e cinco terceiros molares humanos livres de cárie } \\
\text { recém-extraídos foram selecionados. A aplicação de CHX ou MI } \\
\text { por } 60 \text { segundos após o condicionamento para estabilizar a DHL } \\
\text { melhora a força de ligação imediata por meio da inativação de } \\
\text { proteases endógenas. Assim, os inibidores de MMP podem } \\
\text { prevenir a degradação das fibras de colágeno, mas a eficácia de } \\
\text { longo prazo de diferentes inibidores de MMP justifica um estudo } \\
\text { mais aprofundado. }\end{array}$ \\
\hline
\end{tabular}




\begin{tabular}{|c|c|c|c|c|}
\hline $\begin{array}{l}\text { Mazzoni et } \\
\text { al. }\end{array}$ & 2015 & $\begin{array}{l}\text { Journal of Dental } \\
\text { Research }\end{array}$ & $\begin{array}{l}\text { Descrever as MMPs e sua } \\
\text { presença na dentina, } \\
\text { focando no seu papel na } \\
\text { cárie e na perda de } \\
\text { colágeno na camada } \\
\text { híbrida em restaurações } \\
\text { de resina composta. }\end{array}$ & $\begin{array}{l}\text { Os inibidores enzimáticos podem desempenhar um papel crucial } \\
\text { em protocolos terapêuticos e preventivos. No entanto, são } \\
\text { necessários mais estudos sobre novos produtos químicos capazes } \\
\text { de inibir a atividade de MMP e contribuir efetivamente para a } \\
\text { prevenção da cárie e melhorar a estabilidade da interface } \\
\text { adesiva. }\end{array}$ \\
\hline Zheng et al. & 2015 & $\begin{array}{l}\text { Operative } \\
\text { Dentistry }\end{array}$ & $\begin{array}{l}\text { Analisar o efeito de } \\
\text { diferentes inibidores de } \\
\text { MMP na resistência de } \\
\text { união à microtração } \\
\text { (microTBS) de um } \\
\text { adesivo condiciona e lava } \\
\text { e autocondicionante após } \\
9 \quad \text { meses de } \\
\text { envelhecimento. }\end{array}$ & $\begin{array}{l}\text { Quarenta molares humanos extraídos e sadios foram } \\
\text { selecionados para este estudo. O MicroTBS apenas do adesivo } \\
\text { condiciona e lava diminuiu significativamente com o } \\
\text { envelhecimento. Para Optibond FL, o pré-tratamento com } 2 \% \text { de } \\
\text { CHX, } 0,05 \% \text { de extrato de chá verde e } 0,2 \mathrm{mM} \text { de galardina } \\
\text { revelou valores de força de ligação semelhantes ao microTBS } \\
\text { inicial e maiores em comparação com a dentina envelhecida não } \\
\text { tratada. Não houve diferença entre os grupos de Clearfil SE } \\
\text { Bond. }\end{array}$ \\
\hline $\begin{array}{l}\text { Göstemeyer e } \\
\text { Schwendicke }\end{array}$ & 2016 & $\begin{array}{l}\text { Journal } \\
\text { Dentistry }\end{array}$ & $\begin{array}{llr}\text { Investigar } & \text { o } & \text { pré- } \\
\text { tratamento } & & \text { com } \\
\text { inibidores de } & \text { MMP } \\
\text { qualitativamente } & \text { e por } \\
\text { meta e análise sequencial } \\
\text { de ensaio. }\end{array}$ & $\begin{array}{l}\text { De } 1.006 \text { estudos identificados, } 18 \text { foram avaliados em texto } \\
\text { completo e } 10 \text { incluídos. O seguimento variou de } 6 \text { a } 36 \text { meses. } \\
\text { Não há evidências suficientes para recomendar ou refutar o pré- } \\
\text { tratamento da cavidade inibitória da degradação antes da } \\
\text { colocação adesiva de restaurações à base de resina. Isso pode } \\
\text { mudar a longo prazo. }\end{array}$ \\
\hline Favetti et al. & 2017 & $\begin{array}{l}\text { Journal } \\
\text { Dentistry }\end{array}$ & $\begin{array}{l}\text { Avaliar o efeito do pré- } \\
\text { tratamento com CHX } \\
\text { como coadjuvante na } \\
\text { retenção de restauração } \\
\text { de lesões cervicais não } \\
\text { cariosas, após } 36 \text { meses. }\end{array}$ & $\begin{array}{l}\text { A taxa de sobrevivência das restaurações após } 36 \text { meses de } \\
\text { seguimento foi de } 76,1 \% \text {. Não houve diferença nas taxas de } \\
\text { retenção e falha entre o grupo experimental e o grupo } \\
\text { controle. Houve uma tendência de falha aumentada quando as } \\
\text { restaurações foram localizadas subgengival em comparação ao } \\
\text { nível gengival ou supragengival. }\end{array}$ \\
\hline Zheng e Chen & 2017 & Scientific Reports & $\begin{array}{l}\text { Avaliar e comparar o } \\
\text { efeito de diferentes } \\
\text { inibidores exógenos de } \\
\text { MMP nas propriedades } \\
\text { físicas dos adesivos } \\
\text { dentais, resistência de } \\
\text { união, r micro } \\
\text { permeabilidade } \\
\text { atividade do substrato de } \\
\text { MMP. }\end{array}$ & $\begin{array}{l}\text { Um total de } 1603^{\circ} \text { molares extraídos foram usados. Inibidores } \\
\text { de MMP do grupo CHX } 2 \% \text {, doxiciclina } 2 \% \text { e proantocianidinas } \\
5 \% \text { poderiam ser usados para o pré-tratamento de superfícies de } \\
\text { dentina para aumentar o adesivo da resina dentinária. A } \\
\text { aplicação do inibidor pelo tempo de } 1 \text { minuto após o } \\
\text { condicionamento melhora significativamente a resistência de } \\
\text { união, a exposição às fibras de colágeno e uniformiza a forma } \\
\text { densa da camada híbrida o que evita sua degradação. Os efeitos } \\
\text { a longo prazo devem ser analisados em estudos longitudinais } \\
\text { futuros. }\end{array}$ \\
\hline Moraes et al. & 2020 & $\begin{array}{l}\text { Restorative } \\
\text { Dentistry } \\
\text { Endodontics }\end{array}$ & $\begin{array}{l}\text { Revisar as estratégias } \\
\text { utilizadas para } \text { inibir } \\
\text { MMPs que podem } \\
\text { alcançar uma adesão } \\
\text { material-dente de } \\
\text { duração. }\end{array}$ & $\begin{array}{l}\text { Os inibidores seletivos de MMPs prometem ser o futuro da } \\
\text { prevenção da proteólise da dentina e o conhecimento sobre sua } \\
\text { funcionalidade deve ser considerada para sintetizar fármacos } \\
\text { capazes de bloquear de forma eficiente e seletiva sua ativação, } \\
\text { superarando as limitações atuais, com fácil aplicação clínica e } \\
\text { longa duração efeito. }\end{array}$ \\
\hline Kiuru et al. & 2021 & $\begin{array}{l}\text { International } \\
\text { Journal } \\
\text { Dentistry }\end{array}$ & $\begin{array}{l}\text { Revisar sistematicamente } \\
\text { a literatura para estudos } \\
\text { que avaliaram o efeito } \\
\text { dos inibidores de MMP } \\
\text { na resistência de união à } \\
\text { dentina imediata e } \\
\text { envelhecida. }\end{array}$ & $\begin{array}{l}\text { Duas bases de dados foram pesquisadas e, de um total de } 740 \\
\text { artigos, } 43 \text { foram aceitos para revisão completa. } 21 \text { artigos com } \\
\text { tratamentos de CHX } 0,2 \%-2 \% \text { foram incluídos para meta- } \\
\text { análise. Nenhuma diferença imediata significativa foi observada } \\
\text { entre } \mathrm{CHX} \text { e o controle. As forças de união na CHX foram } \\
\text { maiores do que no grupo de controle após o envelhecimento. As } \\
\text { fraturas ocorridas na interface adesiva aumentaram após o } \\
\text { envelhecimento. Mais estudos de longo prazo com menor risco } \\
\text { de viés devem ser realizados. }\end{array}$ \\
\hline
\end{tabular}

Fonte: Autores. 


\section{Discussão}

Atualmente, segundo Zheng \& Chen (2017), um dos grandes desafios para a odontologia adesiva é manter conservada a integridade da camada híbrida em restaurações. É sabido que, o fator dificultador está relacionado a ação das MMPs, que estão presentes na dentina e na saliva, e degradam os filamentos colágenos desprotegidos.

A falta de suporte das fibrilas acontece quando o colágeno desmineralizado não é vedado corretamente pelo adesivo. Isso se dá, muitas vezes, pela dificuldade no controle da umidade de forma correta após o condicionamento ácido, impedindo o acesso das fibras pelos monômeros (Li et al., 2015).

De acordo com Moraes et al. (2020), a hidrólise acontece quando há presença de água residual e umidade significativa entre os túbulos, e o adesivo não consegue desempenhar seu papel de encobrimento das fibrilas. Do mesmo modo, quando ocorre a desidratação da dentina, ela tende a ter as fibras colágenas colapsadas ou colabadas, que também dificulta a perfusão do monômero adesivo.

Como aponta Li et al. (2015), independentemente do sistema adesivo usado, as falhas no molhamento das fibrilas colágenas podem eventualmente acontecer e, consequentemente, causar comprometimentos na adesão. Pela necessidade de união ao substrato úmido, encontra-se na composição dos adesivos, componentes iônicos e hidrofílicos o que gera um aumento de permeabilidade, tornando a camada híbrida ainda mais suscetível a hidrólise.

Além da hidrólise, as fibrilas colágenas desprotegidas se tornam suscetíveis também a degradação pela ação enzimática. Essas enzimas fazem parte dos $10 \%$ de proteínas não colágenas da MEC da dentina, restando $90 \%$ de colágeno, segundo Mazzoni et al. (2015). Entre elas encontram-se as MMPs. Elas estão também espalhadas por quase todos os tecidos do nosso corpo e apresentam-se em 25 tipos, contudo presentes na dentina, podemos citar principalmente as MMP - 2, -9 (gelatinases), -8, -13 (colagenase) e -20 (enamelisina) (Li et al., 2014; Moraes et al., 2020).

Essas enzimas são endopeptidases dependentes de cálcio e zinco, são produzidas pelos odontoblastos e atuantes na dentinogênese. Após esse ciclo, elas se encontram desativadas uma vez que, na dentina mineralizada, os cristais de apatita bloqueiam o acesso direto ao colágeno. Mas, ao estarem diante de certos agentes químicos, térmicos ou pH abaixo de 4,5, como em um processo carioso ou em um procedimento adesivo, que são fatores danificadores das apatitas, as MMPs se reativam e podem degradar os componentes da MEC. Por isso, busca-se estratégias para driblar essa ativação (Zheng et al., 2015; Mazzoni et al., 2015; Moraes et al., 2020).

No procedimento adesivo, essa ativação se dá pela remoção da superfície mineral durante o condicionamento para estabelecer a camada híbrida, em que as proteases que estavam aprisionadas, como a MMP, podem ser liberadas. Em dentinas cariadas, há também o aumento na atividade proteolítica devido ao constante ciclo de desmineralização e remineralização que essa dentina sofre (Mazzoni et al., 2015; Zheng \& Chen, 2017; Moraes et al., 2020).

É compreendido que a CHX se comporta de forma inibitória sobre essa enzima, alterando sua estrutura e quelando os íons metálicos $\left(\mathrm{Ca}^{2+} \mathrm{Zn}^{2+}\right)$ essenciais para sua ativação, o que quebraria essa sequência de degradação, gerando interesse em pesquisa pela classe de odontólogos (Zheng \& Chen, 2017). Segundo Montagner et al. (2014), existem diferentes formas de incluir a CHX ao protocolo restaurador. Pode-se incorporá-la ao ataque ácido e enxaguá-la após aplicação, incluir no sistema adesivo ou diretamente sobre a superfície sem enxague, após o ataque ácido. A última forma, como primer terapêutico, é a mais empregada.

Moraes et al. (2020) aponta ainda, alguns estudos que fizeram o uso do mesmo modo, do diacetato de clorexidina, que pode se apresentar também na versão em pó incorporado ao sistema adesivo, o que resolveria o problema de manutenção de umidade, um dificultador para a penetração do monômero. O mesmo não interferiu na sorção de água, mantendo as propriedades do sistema adesivo ideais. Os mesmos autores ainda apontam para o uso de outros inibidores com 
maior seletividade e substantividade, que poderiam melhorar a especificidade da inibição, visando MMPs inerentes a degradação da camada híbrida.

Montagner et al. (2014), em sua análise de estudos in vitro com adesivos convencionais e autocondicionantes, concluíram que o uso da $\mathrm{CHX} 2 \%$ não influenciou a força de união imediata, mas diminuiu a perda de resistência após o envelhecimento. Entretanto, de acordo com os autores, a tendência é de que essa promoção de estabilidade em períodos maiores que 12 meses não se mantenha.

Contradizendo o estudo acima, para Li et al. (2015) e Zheng e Chen (2017), a aplicação da CHX por um minuto após o condicionamento ácido estabilizou a camada híbrida por meio da inativação das proteases endógenas, o que preveniu a degradação das fibras colágenas e melhorou a força de união imediata.

Kiuru e colaboradores (2021), em uma meta-análise, concluíram que a CHX não tem efeito sobre a força de união imediata, mas, em contraste com isso, os estudos de 6, 12 e 24 meses demonstraram qualidade superior comparado ao controle. Seguindo esse padrão, estudos com mais de 24 meses mostraram ainda mais aumento na diferença entre restaurações tratadas e não tratadas com CHX.

Mazzoni et al. (2015) reconheceram a importância do uso de inibidores de MMP na manutenção da estabilidade da ligação dente-resina e inclusive no controle da progressão da cárie. Mas concluíram que, mais estudos são necessários para entender de fato os mecanismos e usar esses agentes químicos da forma mais proveitosa possível.

A CHX, ainda que amplamente estudada e demonstrando bons resultados na quelação dos íons metálicos, como o cálcio, quando entra em contato com os sistemas adesivos que também liberam esse íon, pode ter a perda de seu efeito inibitório a longo prazo. Por possuir um mecanismo de ligação apenas eletrostático, há a possibilidade de que as características inibitórias da CHX sejam enfraquecidas pelo deslocamento da mesma por cátions do fluido dentinário ou da saliva (Mazzoni et al., 2015; Moraes et al., 2020).

Após o tratamento prévio com CHX, Zheng e colaboradores (2015) encontraram nos adesivos convencionais uma superior resistência a microtração (microTBS) comparado ao sistema adesivo autocondicionante quando tratados no tempo de 9 meses (Zheng et al., 2015). Zheng e Chen (2017), encontraram os melhores resultados na exposição das fibrilas de colágeno, microTBS e micropermeabilidade, entre os grupos de inibidores de MMP pesquisados e o controle, na CHX.

Entretanto, Göstemeyer e Schwendicke (2016), classificaram os ensaios clínicos randomizados de sua busca como fracos devido ao alto viés e as poucas evidências científicas clínicas, tanto no sistema autocondicionante quanto no condiciona e lava. Essa baixa evidência disponível, faz os mesmos não recomendarem e nem discriminarem o uso do inibidor.

Favetti et al. (2017), em um estudo in vivo sobre o uso da CHX em lesões cervicais não cariosas com 36 meses de acompanhamento, chegaram à conclusão de que o tratamento ou não da superfície com o inibidor gerou os mesmos resultados de retenção. Os autores consideram, ainda, que o aumento de uma fase no procedimento adesivo não mostrou até então, nenhuma vantagem.

Perante aos dados coletados fica claro que este ainda é um assunto que demanda maiores e mais longas provas cientificas devido a heterogeneidade dos resultados entre autores. Entretanto, nenhum estudo demonstrou que o uso do inibidor seria prejudicial a longevidade da restauração.

\section{Conclusão}

Diante do exposto, entende-se os resultados promissores sobre o uso da CHX a curto e médio prazo e seu nível de substantividade, entretanto há a necessidade da revisão de estudos mais extensos e in vivo para estabelecer uma conclusão sobre os efeitos do seu emprego a longo prazo. Da mesma maneira, a extensão de estudos faz-se necessária entre os tipos de sistemas adesivos pois nenhum dos autores elucida de forma significativa a comparação da melhora de resultados entre eles. 
Em suma, conclui-se que bem como sua eficácia a longo prazo, entre 6 e 36 meses, sua indicação de uso também não pode ainda ser estabelecida, entretanto não há demonstrações de que a mesma trará maléficos para a união.

\section{Referências}

Baehni, P. C., \& Takeuchi, Y. (2003). Anti-plaque agents in the prevention of biofilm-associated oral diseases. Oral diseases, 9 Suppl 1, 23-29. https://doi.org/10.1034/j.1601-0825.9.s1.5.x

Bounocore M. G. (1955). A simple method of increasing the adhesion of acrylic filling materials to enamel surfaces. Journal of dental research, 34(6), 849853. https://doi.org/10.1177/00220345550340060801

Estrela, C. (2018). Metodologia Científica: Ciência, Ensino, Pesquisa. Editora Artes Médicas.

Favetti, M., Schroeder, T., Montagner, A. F., Correa, M. B., Pereira-Cenci, T., \& Cenci, M. S. (2017). Effectiveness of pre-treatment with chlorhexidine in restoration retention: A 36-month follow-up randomized clinical trial. Journal of dentistry, 60, 44-49. https://doi.org/10.1016/j.jdent.2017.02.014

Göstemeyer, G., \& Schwendicke, F. (2016). Inhibition of hybrid layer degradation by cavity pretreatment: Meta- and trial sequential analysis. Journal of dentistry, 49, 14-21. https://doi.org/10.1016/j.jdent.2016.04.007

Hamdan-Nassar, T., Bellot-Arcís, C., Paredes-Gallardo, V., García-Sanz, V., Pascual-Moscardó, A., Almerich-Silla, JM, \& Montiel-Company, JM (2019). Efeito da clorexidina a 2\% após o condicionamento ácido na resistência de união à microtração de restaurações de resina: uma meta-análise. Medicina (Kaunas, Lituânia), 55 (12), 769. https://doi.org/10.3390/medicina55120769

Hashimoto, M., Fujita, S., Nagano, F., Ohno, H., \& Endo, K. (2010). Ten-years degradation of resin-dentin bonds. European journal of oral sciences, 118(4), 404-410. https://doi.org/10.1111/j.1600-0722.2010.00744.X

Kiuru, O., Sinervo, J., Vähänikkilä, H., Anttonen, V., \& Tjäderhane, L. (2021). MMP Inhibitors and Dentin Bonding: Systematic Review and MetaAnalysis. International journal of dentistry, 2021, 9949699. https://doi.org/10.1155/2021/9949699

Li, H., Li, T., Li, X., Zhang, Z., Li, P., \& Li, Z. (2015). Morphological effects of MMPs inhibitors on the dentin bonding. International journal of clinical and experimental medicine, 8(7), 10793-10803 https://www.ncbi.nlm.nih.gov/pmc/articles/PMC4565256/

Liu, Y., Tjäderhane, L., Breschi, L., Mazzoni, A., Li, N., Mao, J., Pashley, D. H., \& Tay, F. R. (2011). Limitations in bonding to dentin and experimental strategies to prevent bond degradation. Journal of dental research, 90(8), 953-968. https://doi.org/10.1177/0022034510391799

Lobo, T. R. S. (2013). Influência do uso do digluconato de clorexidina como inibidor de metaloproteinase na resistência adesiva e dureza da camada híbrida e camada de adesivo. Dissertação de Mestrado, Faculdade de Odontologia, Universidade de São Paulo, São Paulo. Doi: 10.11606/D.23.2013.tde-17122013155843

Martins, G. C, Franco, A. P. G. O., Godoy, E. P., Maluf, D. R., Gomes, J. C., \& Gomes, O. M. M. Adesivos Dentinários. Revista Gaúcha de Odontologia, 56(4), 429-436, 2008. http://www.revistargo.com.br/include/getdoc.php?id=2917\&article=790\&mode=pdf

Maya, J. J., Ruiz, S. J., Pacheco, R., Valderrama, S. L., \& Villegas, M. V. (2011) Papel da clorexidina na prevenção de infecções relacionadas aos cuidados de saúde. Infectio, 15(2), 98-107, Retrieved 19/10/2021, from https://www.revistainfectio.org/index.php/infectio/article/view/12

Mazzoni, A., Tjäderhane, L., Checchi, V., Di Lenarda, R., Salo, T., Tay, FR, Pashley, DH, \& Breschi, L. (2015). Papel das MMPs de dentina na progressão da cárie e na estabilidade da união. Journal of Dental Research, 94(2), 241-251. https://doi.org/10.1177/0022034514562833

Medeiros, A. F., Avelar, W. V., Lima, D. A., Queiroz, A. M., Campos, F., Vasconcelos, R. G., \& Vasconcelos, M. G. (2019) Os efeitos das Metaloproteinases da matriz extracelular - MMPS e clorexidina no mecanismo de adesão dentária. Rev. Salusvita, 38(4), 1127-1149. Retrieved 19/10/2021, from https://secure.unisagrado.edu.br/static/biblioteca/salusvita/salusvita_v38_n4_2019/salusvita_v38_n4_2019_art_17.pdf

Montagner, A. F., Sarkis-Onofre, R., Pereira-Cenci, T., \& Cenci, M. S. (2014). MMP Inhibitors on Dentin Stability: A Systematic Review and Metaanalysis. Journal of dental research, 93(8), 733-743. https://doi.org/10.1177/0022034514538046

Moraes, I., do Nascimento, T. G., da Silva, A. T., de Lira, L., Parolia, A., \& Porto, I. (2020). Inhibition of matrix metalloproteinases: a troubleshooting for dentin adhesion. Restorative dentistry \& endodontics, 45(3), e31. https://doi.org/10.5395/rde.2020.45.e31

Ou, Q., Hu, Y., Yao, S., Wang, Y., \& Lin, X. (2018). Effect of matrix metalloproteinase 8 inhibitor on resin-dentin bonds. Dental materials : official publication of the Academy of Dental Materials, 34(5), 756-763. https://doi.org/10.1016/j.dental.2018.01.027

Pashley, D. H., Tay, F. R., Yiu, C., Hashimoto, M., Breschi, L., Carvalho, R. M., \& Ito, S. (2004). Collagen degradation by host-derived enzymes during aging. Journal of dental research, 83(3), 216-221. https://doi.org/10.1177/154405910408300306

Rajkumar, D. S., \& Mariswamy, A. B. (2021). Comparative evaluation of Emblica officinalis as an etchant and an MMP inhibitor with orthophosphoric acid and chlorhexidine on the microshear bond strength of composite resin: an ex vivo study. Restorative dentistry \& endodontics, 46(3), e36. https://doi.org/10.5395/rde.2021.46.e36

Reis, A.; Loguercio, A. D. (2007) Materiais Dentários Restauradores Diretos: dos Fundamentos à Aplicação Clínica (1ª ed) São Paulo: Santos Editora.

Schimidt, M. F. (2019) Sistemas adesivos e suas abordagens atuais na resistências de união à dentina. 2019.24 f. Dissertação (Trabalhos de Conclusão de Curso de Graduação de Odontologia) Universidade Federal Do Rio Grande Do Sul, Porto Alegre, Rio Grande Do Sul, Brasil. https://lume.ufrgs.br/handle/10183/205709 
Research, Society and Development, v. 10, n. 15, e80101522642, 2021

(CC BY 4.0) | ISSN 2525-3409 | DOI: http://dx.doi.org/10.33448/rsd-v10i15.22642

Strobel, S., \& Hellwig, E. (2015). The effects of matrix-metallo- proteinases and chlorhexidine on the adhesive bond. Swiss dental journal, 125(2), 134-145. https://www.sso.ch/fileadmin/pubmed/sdj-2015-02-01.pdf

Silva, E., Vasconcelos, M., \& Vasconcelos, R. (2019). Influência de inibidores de metaloproteinases na degradação da camada híbrida. Revista Da Faculdade De Odontologia - UPF, 24(1), 162-169. https://doi.org/10.5335/rfo.v24i1.9119

Tekçe, N., Tuncer, S., Demirci, M., \& Balci, S. (2016). Do matrix metalloproteinase inhibitors improve the bond durability of universal dental adhesives?. Scanning, 38(6), 535-544. https://doi.org/10.1002/sca.21293

Ten Cate, A. R. (1994) Oral Histology. Development, Structure and Function (4 ed.) Mosby, St. Louis.

Tjäderhane, L., Nascimento, F. D., Breschi, L., Mazzoni, A., Tersariol, I. L., Geraldeli, S., Tezvergil-Mutluay, A., Carrilho, M. R., Carvalho, R. M., Tay, F. R., \& Pashley, D. H. (2013). Optimizing dentin bond durability: control of collagen degradation by matrix metalloproteinases and cysteine cathepsins. Dental materials: official publication of the Academy of Dental Materials, 29(1), 116-135. https://doi.org/10.1016/j.dental.2012.08.004

Tran, X. V., \& Tran, K. Q. (2021). Microleakage and characteristics of resin-tooth tissues interface of a self-etch and an etch-and-rinse adhesive systems. Restorative dentistry \& endodontics, 46(2), e30. https://doi.org/10.5395/rde.2021.46.e30

Zheng, P., \& Chen, H. (2017). Evaluate the effect of different mmps inhibitors on adhesive physical properties of dental adhesives, bond strength and mmp substarte activity. Scientific reports, 7(1), 4975. https://doi.org/10.1038/s41598-017-04340-1

Zheng, P., Zaruba, M., Attin, T., \& Wiegand, A. (2015). Effect of different matrix metalloproteinase inhibitors on microtensile bond strength of an etch-andrinse and a self-etching adhesive to dentin. Operative dentistry, 40(1), 80-86. https://doi.org/10.2341/13-162-L 